\title{
Participatory and prospective value network analysis: supporting transition towards biofuels in Finnish road transport
}

\author{
Anu Tuominen ${ }^{1}$ • Nina Wessberg ${ }^{1}$ - Anna Leinonen ${ }^{1}$ \\ Received: 13 March 2015 / Accepted: 13 May 2015 /Published online: 9 June 2015 \\ (C) The Author(s) 2015. This article is published with open access at Springerlink.com
}

\begin{abstract}
If the European energy and transport sectors are to meet the 2050 energy and climate policy targets, major sociotechnical change (transition) is necessary. Along with new technologies, changes are required also in other societal functions such as business models and consumer habits. The transition will require cooperation between public and private actors. This paper discusses the socio-technical change towards a 2050 road transport system based on renewable energy. More precisely, it proposes a novel, participatory foresight approach in the context of biofuels in Finland. The participatory and prospective value network analysis outlined in the paper combines elements from the fields of foresight, sociotechnical change on multiple levels and value network analysis. It presents a novel, policy and business-relevant application with a set of practical tools to support development of implementation strategies, but also to boost new business opportunities in the fields of energy and transport.
\end{abstract}

Keywords Participatory foresight $\cdot$ Multi-level perspective . Value network · Transport system · Energy system · Transition

\section{Introduction and research questions}

Sustainable energy technologies are driven especially by the climate change challenge, which necessitates a paradigm shift

This article is part of the Topical Collection on The Future of Transport in Europe, guest-edited by Hans-Liudger Dienel and Massimo Moraglio.

Anu Tuominen

anu.tuominen@vtt.fi

1 VTT Technical Research Centre of Finland Ltd., P.O.Box 1000, Espoo 02044, VTT, Finland also in global energy production and consumption structures. Currently, about $20 \%$ of the Nordic $\mathrm{CO}_{2}$ emissions are due to the transport sector. If the national energy and transport systems are to meet the European energy and climate policy goals, a major transition in both systems is necessary. The transition requires cooperation between public and private actors. In our view policy decisions should create preconditions for companies to provide renewable energy solutions in a manner which would attract other companies and consumers to implement and use them.

The EU White Paper proposed a $60 \%$ reduction of transport $\mathrm{CO}_{2}$ emissions from 1990 level by 2050 [1], if transport was to accept a 'fair' share of the total reduction. There is, however, also a debate in the EU about the impact of the $80 \%$ reduction target on the EU Roadmap for moving to a competitive low-carbon economy in 2050 [2]. In the latest proposal from the Commission [3], emissions from sectors outside the EU Emission Trading System (including transport) would need to be cut by $30 \%$ below the 2005 level by 2030 . This will need to be translated into Member State targets. In this proposal, renewable energy will play a key role in the transition towards a competitive, secure and sustainable energy system. The Commission proposes an objective of increasing the share of renewable energy to at least $27 \%$ of the EU's energy consumption by 2030. The European Council has endorsed this target which is binding at the EU level.

A socio-technical system and its transition from one configuration to another can be studied, e.g., using a Multi-Level Perspective (MLP) [4]. In this paper, we aim to expand the scientific discussion on the transition on multiple levels (e.g., $[5,6])$ towards a sustainable and innovative energy and transport systems to include also future-oriented actor and business perspectives. We do this by presenting an additional element for MLP, namely participatory, prospective value network analysis. The analysis seeks to identify the critical actors and 
business elements in the future transport and energy system value networks in transition towards renewable futures, in our case more precisely, towards renewable biofuels. First, the future context for a prospective value networks is built. Second, the value network actors are identified within the future contexts provided by the scenarios. Third, changes required in the system are clarified by analysing the prospective value networks. All the steps are carried out in a participatory process with both public and private stakeholders.

Traditionally, value chains have been considered in rather short term business opportunity analyses. Our first argument is that private and public actors of the transport and energy systems need to share the same image of the future transport system to anticipate, but more importantly to create future transport and energy markets and demand what is necessary for such a transition. Secondly, the system actors need to widen their scope from linear value chain thinking (e.g., [7-9]) to a transition-oriented network approach. Also Ponte [10] and Riisgaard [11] support the idea that external stakeholders, such as governments, large NGOs, experts, certification bodies and service providers, can have an important say in how value chains are governed. The proposed participatory value network analysis opens up future carriers and barriers for transition and consequently helps actors to steer their actions accordingly in a complementary manner.

More specifically, we address the topic through the following research questions:

- What are the elements of participatory value network analysis towards a biofuel-based transport system?

- How does the analysis help various actors to understand and advance changes required for such a transition?

- What are the benefits of the participatory analysis for public and private decision making?

The paper is based on the TOP-NEST project, which is a Nordic Energy Research-funded effort to explore three renewable energy technology platforms: 1) electricity systems, 2) liquid and gaseous biofuels, and 3) hydrogen systems, and the potential of the systems to give rise to new value networks, creating entrepreneurial opportunities in the road transport sector. In this paper, our focus is on the Finnish biofuel case.

The paper is structured as follows. Theoretical approaches on participatory foresight, transition in multiple levels, value network analysis and needs for an integrated approach in the literature are reviewed in Section 2. Section 3 presents our approach for prospective value chain analysis in transition and applies it to the Finnish case study. Finally, we conclude with a discussion on the theoretical and practical implications of the approach in Section 4.

\section{Theoretical background}

\section{Participatory foresight}

Foresight can be defined as action-oriented and participatory strategic intelligence focused on alternative futures. Knowledge is produced interactively between multiple stakeholders with specific interests and various perspectives towards the topic under exploration. A further aim is to facilitate interaction between the relevant stakeholders and catalyse the desired developments and strategies [12]. Basically foresight is based on present knowledge about future options that are collected and refined with different methods. In strategic decisionmaking, foresight may be applied to identify strategic research needs and emerging technologies, and also to encourage better communication, collaboration and shared commitment between individual companies, across different industrial sectors and among industry, academia and the government [13].

The importance of participation has been studied, e.g., by Nonaka [14], who has stated that there are four ways to exploit the knowledge of individuals: Socialisation, Externalisation, Internalisation and Combination. Tacit knowledge flows from one individual to another by socialisation when people work together and listen to each other. Externalisation, in turn, changes tacit knowledge into the explicit knowledge by articulating and discussing with other people, for example in group work. Individuals' explicit knowledge can be moved to another individual in a combination process where people connect new knowledge to their old knowledge. Finally, knowledge internalisation means that individuals make mental notes of new things. Eerola \& Jörgensen [12] have described these steps in relation to foresight work and different methods used (Fig. 1).

According to [12], when dealing with distributed cognition as well as tacit and explicit knowledge, it seems that multidisciplinary group work is one of the best approaches to combine knowledge and create new valuable ideas. The participatory processes encourage knowledge exchange and develop deeper understanding of central issues important to the future activities.

The use of participatory groups is based on the model of collaborative grading, which states that the results achieved with collaborative work are better than the ones individuals can achieve by working separately [15]. Democracy is also considered in the participatory process. Distributed cognition, existence of explicit and tacit knowledge and well-planned group work facilitation allow good results in participatory groups.

The benefits of participatory processes are numerous. Glenn [16] lists that a participatory process accelerates the implementation of the strategy the process creates, because 
Fig. 1 Different foresight elements in a dynamic process of shared knowledge creation, a SECI perspective [12]

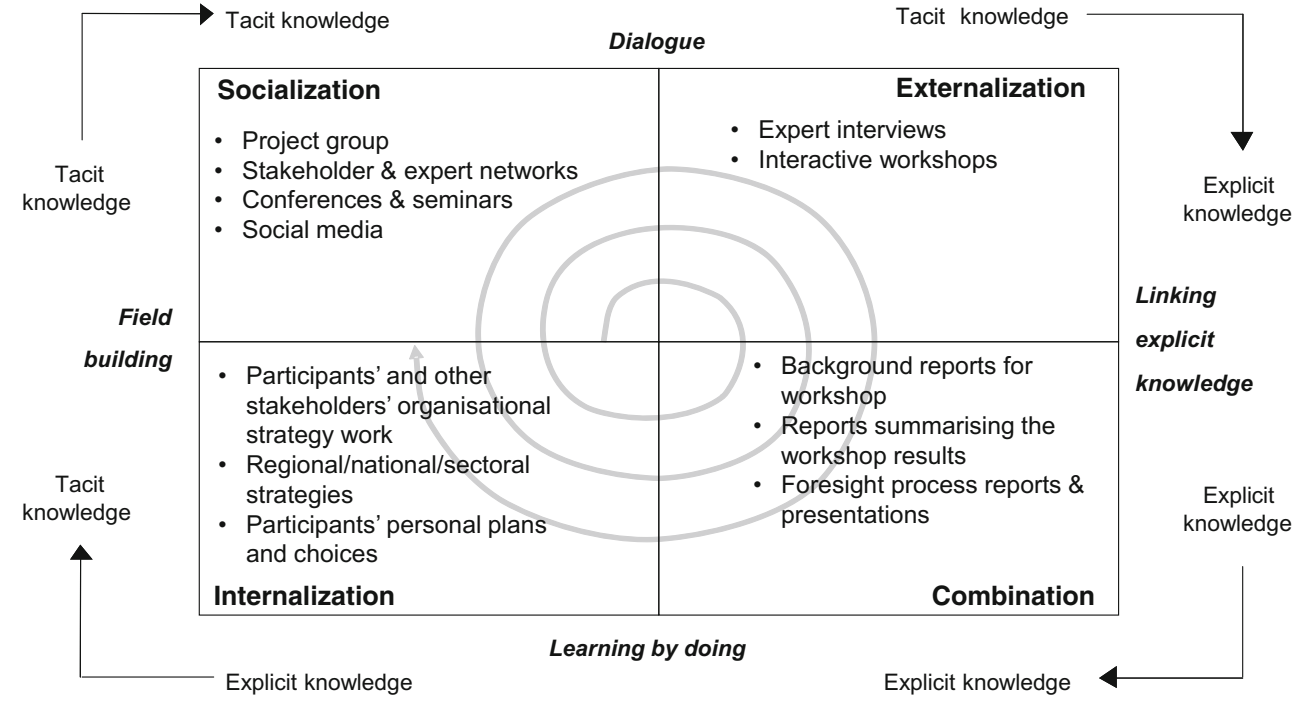

decision makers are already embedded into the decision context through the working process. The shared commitment and values created during the process also seem to cause more successful and effective working processes. It has also been argued that the degree to which different stakeholders are involved in making the decision correlates with public acceptance [16]. In our case, where complementary decisions and actions by public and private stakeholders towards a transport system based on renewable energy (biofuels) are required, a participatory approach is highly relevant.

\section{Multi-level perspective application}

To be able to understand the complexity of the merging energy and transport systems of the future and the multiplicity of the actors involved in transition, we propose application of the MLP framework. The framework has originated in the Netherlands (e.g., $[5,6,17]$ ), to describe the complex societal system change processes. It has been further developed and applied, e.g., in the UK [18]. Recently, Geels has applied the MLP framework to the transport system as he has studied transitions towards low-carbon futures of automobile systems [19].

Three levels of change are abstracted in the MLP model: landscape, regime and niche. Landscape forms an exogenous macro-level environment that influences developments in niches and regimes. General developments in the global operating environment, including e.g., economic, cultural or environmental factors compose the landscape level. The sociotechnical landscape tends to change very slowly since, for example, demographic changes, macro-economics, and cultural changes are slow, some of them taking over a generation to change. Regime refers to the existing structures of the system. The specific form of the regime is mainly shaped and maintained through the mutual adaptation and co-evolution of its actors and elements. Planning and development is based on existing solutions and hence path-dependent decisions and actions dominate. Consequently, the prevailing system acts as a barrier for creation of a new system (in our case a biofuel-based transport system). In the MLP-model radical novelties emerge on the niche level. Niches are local innovative solutions; experiments which may be supported by public subsidies. Niches provide opportunities for learning and incubation of alternative solutions that may gradually become strong enough to challenge the existing regime or adopt and transform the regime towards new directions. Niche-level solutions provide alternative development paths by performing social experiments of, e.g., energy related innovations.

Figure 2 presents our view on applying the MLP to the transport system with the three basic components: users, vehicles and transport infrastructure. In addition, in the middle of these components, all of which interact with one another, the fourth and a fifth components are illustrated: transport services and transport system organisation, governance and regulation. Each of these components is then further elaborated into some key elements that characterise them. For example, transport vehicles and other means of transport rely on alternative technologies and materials, and besides the manufacturing processes, these require also maintenance. Different vehicle solutions make use of different fuels and other energy carriers, and they result in environmental impacts. Furthermore, the use of vehicles involves behavioural and business models, and different types of solutions are available concerning issues such as vehicle ownership (adapted from [20]). The illustration presents also the main elements of the energy system (primary energy sources, production and storage), which are linked to the transport system mainly through energy and transport infrastructures and are crucial for transport operations.

Further, we adjust the transport and energy system components into three levels of the MLP-model and describe them 
Fig. 2 The basic components of transport and related energy systems against the multi-level perspective

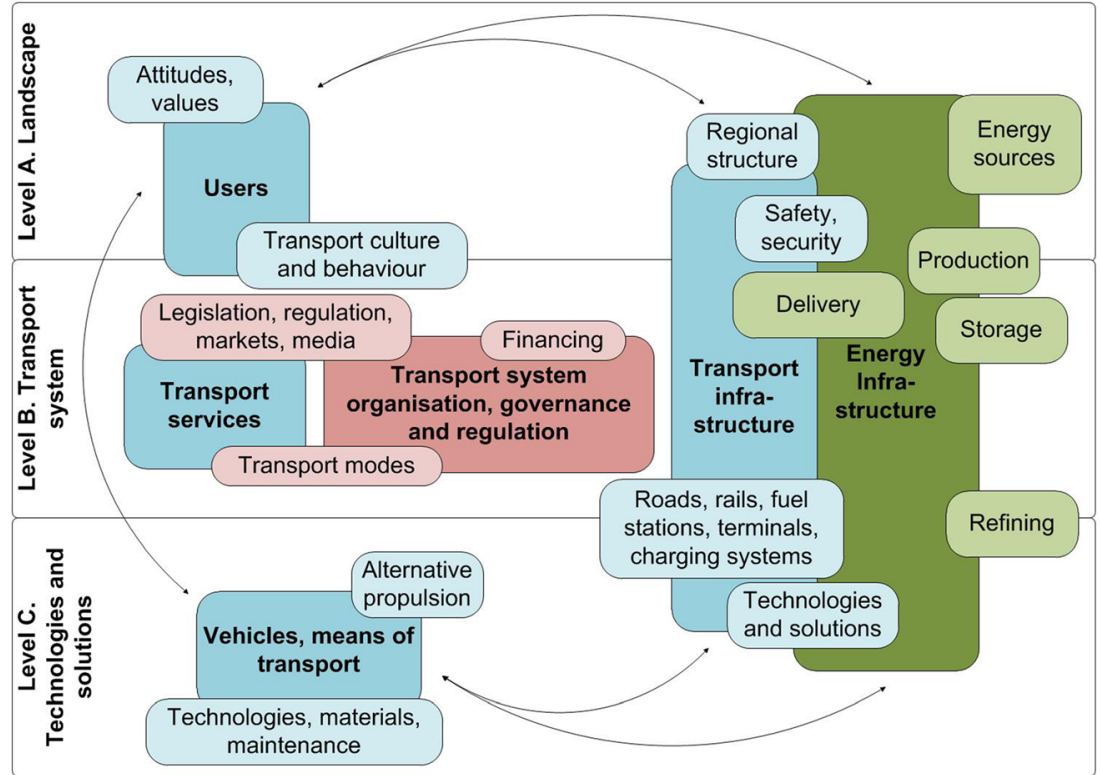

as: 1) landscape, 2) transport system and 3) technologies and solutions. The components and elements of the energy and transport systems are positioned on the most appropriate levels to indicate their main application areas, but it should be acknowledged that the boundaries are not exact. This type of structure is supported also by the recent work by Geels [19], where similar early steps in exploring a MLP framework in the study of transitions in the transport sector are taken. Geels suggests very similar definitions when drafting the automobility system in the context of low-carbon futures. The MLP in structuring the socio-technical system for land-based road transport has also been used by van Bree et al. [21]. In their work, hydrogen and battery-electric vehicle scenarios were mapped when the relationship between car manufacturers and consumers was more closely examined.

In our approach, the key elements of the transport and energy systems, presented in Fig. 2, guide the identification of the key actors in the transport and energy contexts. Basically, the state of the transport system is a result of the measures and actions carried out by the producers, operators and users of the system, the three key actor groups. Producers and operators are organisations or companies, which can be categorised according to their main duties, such as: policy formulation, infrastructure construction and maintenance, production and operation of services for the transport system, and production of transport-related services (e.g., vehicle manufacturing and fuels). Individual people, actually the whole population, are the users of the passenger transport system. In freight transport, users are companies and organisations in the fields of industry, transport and commerce [22]. Producers gather information on the state of the transport system and also receive feedback from customers, that is, the users of the transport system. They make plans on the grounds of expert knowledge (design principles), and decisions based on generic or special decision-making principles. Within the process, information about the system gathered by the producers will be transformed into policy measures, aiming to lead the transport system into a desired (in our case low carbon, based on renewable biofuels) future (e.g., [22-24]).

The system transition towards a new regime is possible only if change processes in the three MLP-levels are synergetic, i.e., the socio-technical change is a result of the interaction and synergies of all levels. One single action cannot change the whole system, but a system innovation is required. Our key argument is that a transformation from the current transport and energy system regime into a new, 2050 renewable energy-based regime is possible only if policy, regulation-, market-, value-, resource-, technology- and infrastructurerelated aspects are changed so that they support each other and hence promote the system transition in the same direction. Institutional and behavioural factors are also issues, which need to be considered carefully in a system change stimulated by the landscape- and niche-level changes.

\section{Value chains and value networks}

When socio-technical change is viewed from a business perspective, it is justified to include the concepts of value chain and value network into discussion. The value chain concept was originally introduced by Porter [25] to include logistics, operations, marketing, sales and services as primary activities. Secondary activities were defined as procurement, human resource management, technological development and infrastructure (ibid.). A value chain has traditionally meant activities needed in order to deliver a specific valuable product and service for the market, such as energy sources or feedstock 
production, energy production, distribution and transportation, retail and consumption. In manufacturing network operations of suppliers, lead producers (such as Original Equipment Manufacturers OEMs) and customers have been seen as independent sequential tasks, which form a value chain. Since the 1990s, however, this pattern has been changing and the theoretical discussion has also emphasised the transfer from value chains to value networks [26, 27].

For our approach, we present the following definitions. A value chain consists of an entire sequence of activities or parties that provide or receive value in the form of products or services. A value network consists of organisations (companies) co-operating with each other to benefit all network members.

A value network generates economic value through complex dynamic exchanges between one or more companies, its customers, suppliers, strategic partners, and the community. Allee [28] argues that value in the networks should be understood as being more than just transactions around goods, services, and revenue. She presents two new currencies of value, which are knowledge value and intangible value or benefits. They are called currencies, because all three serve as a medium of exchange in the value network. All these currencies should be included in the analysis of networked operation in order to understand the value generation of the networks. Another aspect in the analysis is to understand that operation in the value network requires different capacities from the actors than operation in a traditional value or supply chain. The network actors need to understand their position within the network, consider the needs of other actors and rethink their competitive edge [29]. Consequently, business and policy dimensions like future-orientation, knowledge sharing, customer orientation, communication and negotiation skills will become more and more important, and new research knowledge of such issues is needed.

Our approach contributes to rectifying the above deficiencies by presenting a future-oriented method, which we call participatory and prospective value network analysis. As the approach is forward-looking and anticipates value networks that may exist in the long-term future, we consider the traditional analysis of existing value chains too limited in nature. Instead, value network thinking provides us with a potential ground to start the analysis in a totally new future context. Peppard and Rylander [27] present a procedure of Network Value Analysis (NVA), which takes the network-oriented model as a starting point. The aim of NVA is to generate a comprehensive description of where value lies in a network and how value is created. The NVA is based on a step-wise procedure starting from the network objectives definition and identification of network participants to the analysis of value dimensions and influences, and shaping of the final value network. In the beginning of the network analysis, one actor is taken as the network focal. Next, all the other actors that contribute the value the network focal delivers, are identified. A central principle in the analysis is that the network contains roles or functions as nodes, not specific organisation names. This allows carrying out the analysis without fastening on any existing structures and hence diminishes possibilities for pathdependent thinking. Another approach to future-oriented analysis of business models and business ecosystems is presented by Ahokangas et al. [30]. This approach aims at recognition of new business opportunities and developing new business models benefiting from these opportunities. The analysis starts from identification of the key actors and analysis of their needs and benefits in the business ecosystem. The second stage of the analysis is to generate scenarios for the identified ecosystem, so that new business models and value chains can be created. Our approach applies elements from both of the above procedures.

\section{Participatory and prospective value network analysis: case biofuels in Finland}

\section{An overview of the analysis}

This section presents an approach for outlining prospective value networks and chains in transition towards sustainable energy systems in road transport. It enables participative foresight and supports sustainable policy making. The novelty of the approach is in its ability to bring policy and business perspectives and actors into the transition arena to discuss and build the future together through value network analysis, which concretises the actions required in the future. The approach contributes to business renewal of companies and supports market creation by the public sector alike.

The process consists of three phases (Fig. 3): Phase 1: Building future context for value networks; Phase 2: Identification of prospective value networks and network actors; Phase 3: Analysis of the prospective value networks and chains: changes required in the system. Participatory process and external inputs support the core process.

The first phase considers alternative futures and anticipates the context were the prospective value networks will operate. For this purpose, scenario methodology is applied (e.g., [31]). The traditional scenario building process consists of scoping, identification of key factors, analysis of key factors, scenario generation and scenario transfer/use of the scenario. In our case we used literature, futures wheel method and SWOTanalysis in two internal workshops within the TOP-NEST project to create four scenarios, which focus on the images of the future rather than paths from the present to the images.

The goal of the second step is to identify the value network actors and analyse their individual interests, and connections between different actors. The work starts with outlining the network chart covering all possible actors needed in value 
Fig. 3 The participatory and prospective value network analysis content and structure

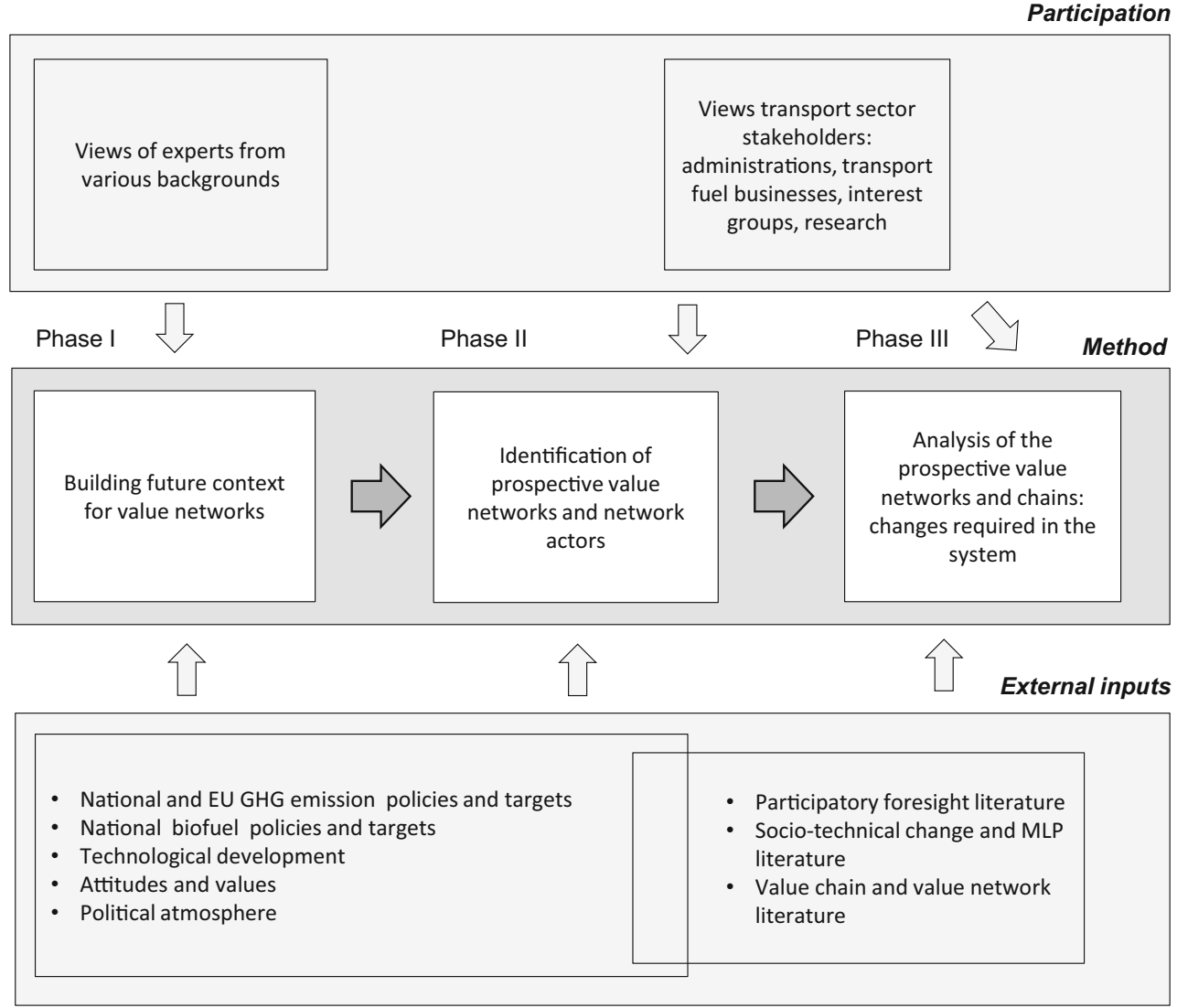

creation. At this point, it is important to analyse the value generation from the perspective of all currencies, i.e., goods and revenue, knowledge, and intangible benefits. In our case, the networks cover activities from energy sources and feedstock production to energy production, distribution and transport, retail and consumption, but regulation, governance and R\&D actors are also included in the analysis.

Thirdly, after generation of the network chart, the connections between the actors are analysed. The analysis covers opportunities and advantages, as well as supportive needs of each actor. Opportunities refer to the possibilities to make profit in the value network and individual value chains within, i.e., how the actor benefits from the value network. Advantages refer to the value created to the customer or the whole network by certain actors. The analysis of the supportive activities is needed to recognise the connections between different actors.

\section{The case study setting - the regime of Finnish biofuel production}

In 2013 the vehicle stock in Finland consisted of 4.95 million vehicles, of which 2.58 million were passenger cars with internal combustion engines (ICE). Of those, $76.8 \%$ used petrol as their power source and $23.2 \%$ diesel [32]. The number of electric vehicles was 170 . In addition, 1700 cars used either biogas or natural gas as their main power source [33]. The statistics indicate that vehicles without internal combustion engines are really a niche in Finland. The vehicle stock changes slowly, because the life time of a car is 18-20 years.

The petroleum infrastructure is well developed in Finland. In 2013 there were 1892 petroleum/diesel service stations in Finland [34]. Hence, a potential alternative to change the transport system towards renewables is a drop-in option where liquid biofuel is added to fossil fuel. Finland has set the highest target, among the EU, for renewable energy share in the transport sector. The target pursues to achieve a $20 \%$ share of renewables in transport by 2020 (Law for biofuel distribution 1420/2010). According to the law, the share of biofuels in fuel mix delivered by the service stations should be at least $8 \%$ by the year $2015,10 \%$ by $2016,12 \%$ by 2017 and $15 \%$ by 2018 . The target is to be achieved by increasing domestic biofuel production. This is supported by taxes (The Law for liquid fuel tax 1399/2010), which are favourable for biofuels. The domestic biofuel production as a replacement for mineral fossil oil is emphasised also in The National Climate and Energy Strategy [35].

The development and production of biofuels has come along well in Finland. Neste Oil Ltd. is the leading biodiesel producer in the world with its NExBTL biodiesel made of vegetable oils and animal-based fatty waste by using hydrogen treatment technology (www.nesteoil.fi). St1 Ltd. 
produces bioethanol from food industry waste and bio-waste, and wood-based sources are also under R\&D (www.st1.fi). In addition, in the beginning of 2015, the traditional pulp and paper producer, UPM Ltd. started to produce advanced biodiesel made from tall oil. Tall oil is a liquid obtained as a by-product of wood pulp manufacture when pulping mainly coniferous trees. The Finnish biofuel story thus shows that the production capacity is growing and at least these three companies are shaping their businesses towards advanced biofuels. Also the political atmosphere is favourable for advanced biofuels.

One of the strengths of biofuels is that they are compatible with existing energy and transport infrastructures. The existing infrastructure of fuel production, storage and distribution is suitable for biofuels. Also, the existing car fleet can use biofuels, at least in combination with traditional fuels. There is a wide variety of raw-material options in Finland, since forests are an abundant natural resource in the country. Possible raw material can be found also from agro biomass, forest biomass and different kinds of industrial and municipal wastes. However, the logistics of biomass-based raw material may be difficult and costly. In Finland, a forest industry-based logistic system already exists, which can be applied also on biofuel system. Waste collecting systems are also well organised in Finland. Raw material options based on industrial waste give opportunities for the development of industrial symbiosis systems (closed systems, closed material flows also across companies).

However, there are also many challenges. Rather low conversion efficiency diminishes the potential of biofuels. It is not efficient to transport biomass raw material for long distances, because of the high water content of the material. Therefore, biofuel production is the most feasible in distributed and local modes of operation. Globally, biomass raw material is a scarce natural resource and the emerging bio economy has also other competing uses for biomass. Further, biofuels may represent an ethical problem for some consumer groups, which may not want to use food as a raw material for fuel. Unsustainable production of biofuel raw material is seen as a threat to the biodiversity and global food production (scarcity of food production land). Extensive certification schemes are needed in order to secure sustainable production, which is costly.

\section{Building the future context for biofuel value networks}

In our future-oriented approach, the temporal scale for the societal transition is of great importance. Our argument is that if the society as a whole will work in the same direction, the transition will be smoother and will take a shorter time. If conflicting interest exist and there is a lack of common goals in society, the transition will be slower. We have named this aspect the policy coherence factor and chose it as the first key dimension for future contexts. For the second key dimension we have chosen the community structure, representing the level of centralisation-decentralisation in urban form, which is important in the transport context. The key dimensions were discussed and identified in two project group workshops.

The top of the vertical axis in Fig. 4 presents coherent, sustainability goal-oriented transition policy, and the bottom incoherent or fragmented policy making. The horizontal dimension presents the community structure, whether it is decentralised (on the left side) or centralised (on the right). This dimension has a strong influence due to short or long distances, transport generation and transport volumes. The
Fig. 4 The principle of scenario creation and the four transport scenarios formulated for 2050

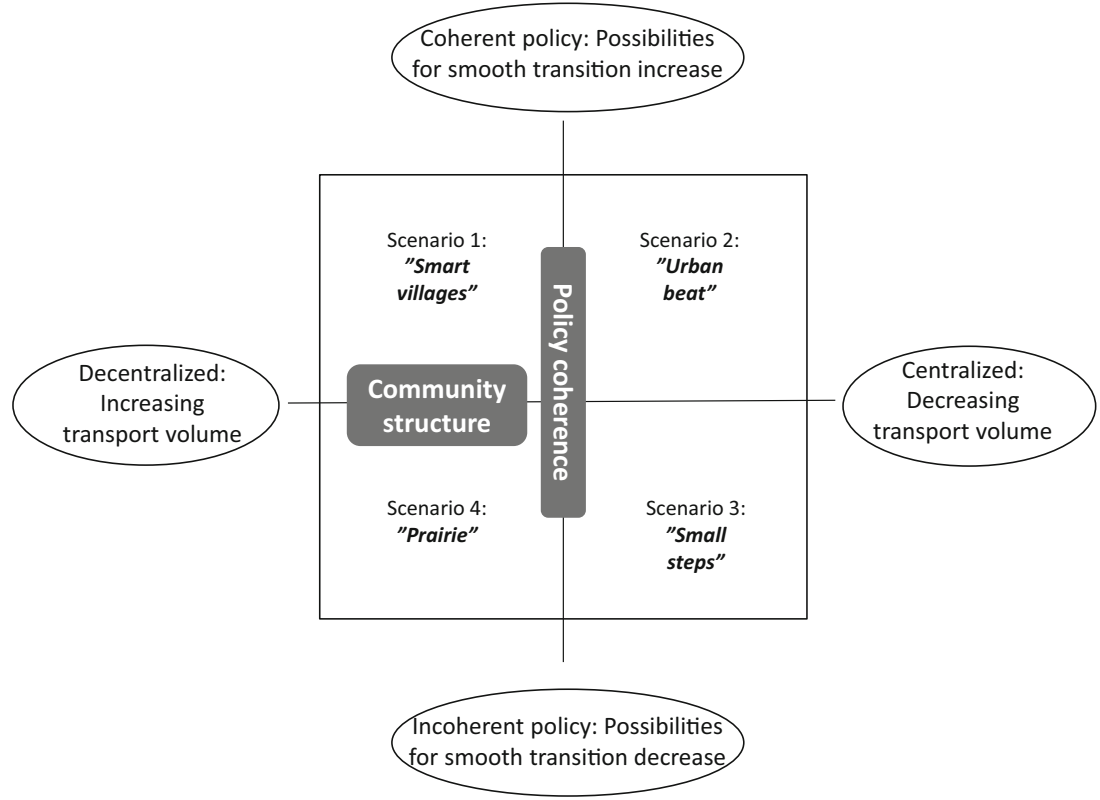


dimensions accommodate also some additional presumptions. In a centralised community, for example, large companies dominate industrial production but in the decentralised community local and small-scale production is preferred.

Using the dimensions presented in Fig. 4, we formulated four different scenarios for 2050, which are presented briefly in Table 1. The scenarios are described through five main elements, which are: (1) users, values and regulation, (2) transport system, (3) transport demand, (4) industry characteristics and structure and (5) technology development. Our motivation for the scenario development was to show that societal contexts set limitations for the development and use of new (biofuel) technologies. The scenarios illustrate alternative future images, and help in the recognition of carriers and barriers for biofuel development and deployment in the future. It was, however, recognised during the work that boundaries between scenarios are not always very clear and that characteristics from several scenarios could be integrated to create the most desirable future image.

\section{Identification of value networks}

One of our key arguments is that identification of value networks and further value chains is important, since they concretise the actions and actors required for renewable biofuel production and use in Finland in the future. In order to identify potential prospective value networks, a workshop for various stakeholders was organised in the Helsinki region, Finland, in February 2014. Altogether 20 stakeholders representing industry, research, associations and government were present at the workshop. The objective of the workshop was twofold. Firstly, to gather information concerning the prospective value networks and value chains for renewable biofuels in a co-creative process. We aimed at recognising all the actors needed for the creation or evolvement of prospective value networks. Secondly, we wanted to test the participatory, prospective value network approach.

In the work shop, the participants were divided into two groups, each of which took a different scenario as a starting point of their analysis. The scenarios applied were the Small Steps scenario and Smart Villages scenario. By selecting two future scenarios we aimed to test whether different external influences bring about different structures in value network actions and actors.

The first task in the workshop was to create an illustration of renewable biofuel value network actions and actors in 2050 within the selected scenario. The participants were advised to consider the various types of actions and actors such as feedstock and energy production, distribution, retail, consumption, regulation \& governance and research \& development.

Figures 5 and 6 present the value networks created. Text boxes in the figures show actions and actors required for functioning networks and arrows illustrate linkages between them. 
Fig. 5 The value network for biofuels in small steps scenario

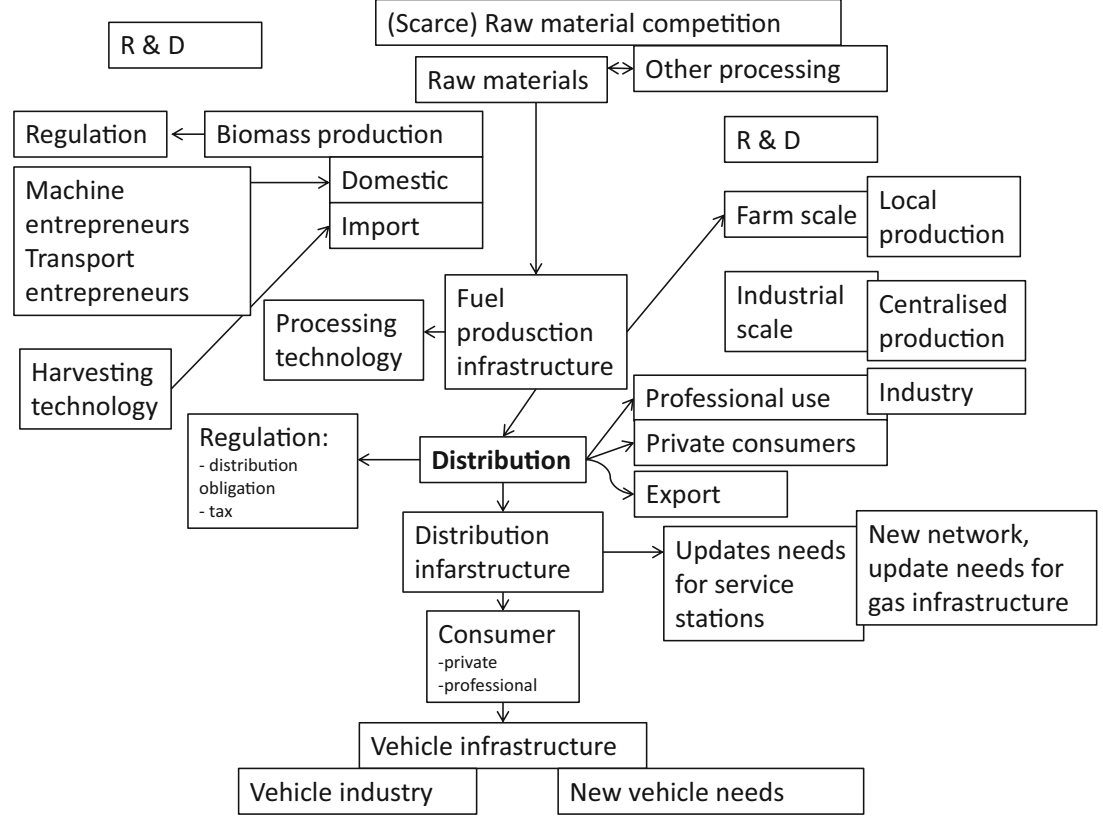

The value network constructed under the Small Steps scenario (Fig. 5) is heavily based on the present transport infrastructure and industrial, organisational and value structures. The other network constructed under the Smart Villages scenario (Fig. 6), emphasises the common good of the village and the role of industrial side streams, instead.

The second task in the workshop was to identify more detailed value chains based on the created value networks. We focused on identifying the actions (actors) needed, value generation, prerequisites for value creation and supporting activities. The template for gathering value chain information is presented in Table 2 .

The workshop participants identified two value chains for renewable biofuels in the Small Steps scenario 2050. These were 'Drop-in' value chain and 'Flexi-fuel' value chain. Dropin biofuels are basically hydrocarbon fuels substantially similar to gasoline. Their commonality is the ability to be used without major changes in current infrastructure. The second value chain focuses on flexible-fuel vehicles (FFVs), which are specially designed to run on gasoline or any blend of up to

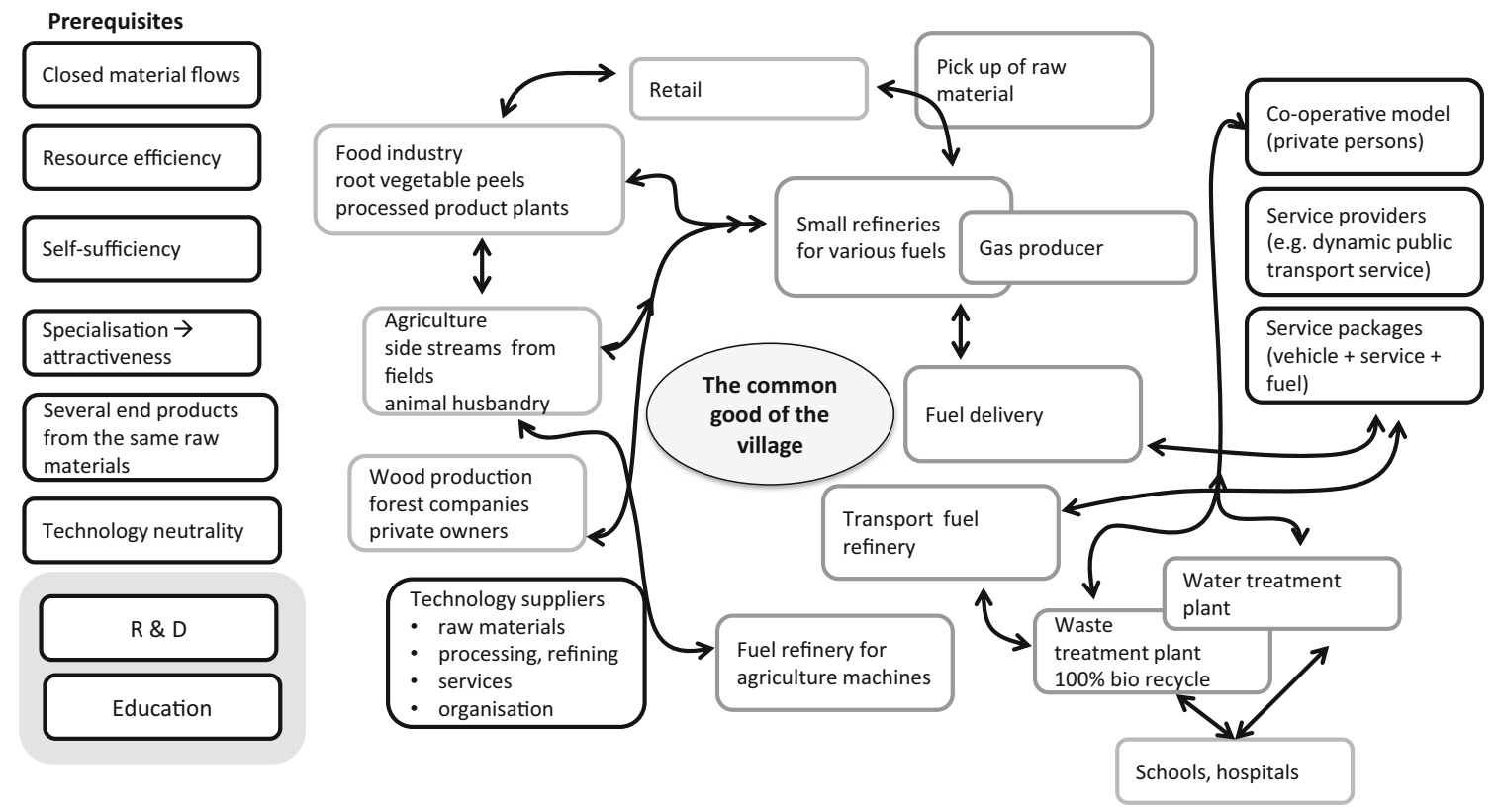

Fig. 6 The value network for biofuels in smart villages scenario 
Table 2 Template for value chain analysis

\begin{tabular}{|c|c|c|c|c|}
\hline Value chain activities & Actors & $\begin{array}{l}\text { Value } \\
\text { creation }\end{array}$ & $\begin{array}{l}\text { Value capture / } \\
\text { Needs }\end{array}$ & $\begin{array}{l}\text { Supportive } \\
\text { activities }\end{array}$ \\
\hline \multicolumn{5}{|l|}{$\begin{array}{l}\text { Energy sources / } \\
\text { Feedstock production }\end{array}$} \\
\hline \multicolumn{5}{|l|}{ Energy production } \\
\hline \multicolumn{5}{|l|}{ Distribution and transport } \\
\hline \multicolumn{5}{|l|}{ Retail } \\
\hline \multicolumn{5}{|l|}{ Consumption } \\
\hline \multicolumn{5}{|l|}{ Regulation \& Governance } \\
\hline Research \& Development & & & & \\
\hline
\end{tabular}

$85 \%$ ethanol. Within the Smart Villages scenario 2050, only one value chain was identified. The three value chains are presented in detail in Appendix 1.

\section{Analysing the prospective value networks and chains - what needs to be changed?}

The created value networks and chains show many differences in requisite changes towards renewable biofuel-based road transport in Finland. In the following, we analyse the results against the MLP framework (Table 3).

In the Drop-in biofuel case in the Small Steps scenario little change is required, since the existing landscape, regime and niche will fulfil the needs of this pathway in both the transport and energy systems. However, biofuel business will increase and this means more biofuel producers and other actors in the value network.

In the flexible fuel case new FFVs are required and the number of fuel stations capable of providing $100 \%$ bioethanol must be increased. In the energy system, waste reuse processes need modifications, since waste is an important rawmaterial of bioethanol.

Biofuels in the Smart Villages scenario highlights the need for transition towards a circular economy where no waste is created, but all the material and energy is cycling in close loops, for instance providing energy for transport. In the value network new service providers will provide services where transport is integrated into other businesses. This integration increases the business potential of biofuels.

The main points of the analysis are gathered in Table 3, where the changes needed in the three MPL-levels are visualised.

The examples show that selection of different scenarios as a starting point for the value network generation resulted in different outcomes. This suggests that the selected scenario-based approach is valuable in prospective value network analysis, because it can produce broader understanding about future conditions and their effect on value network development.

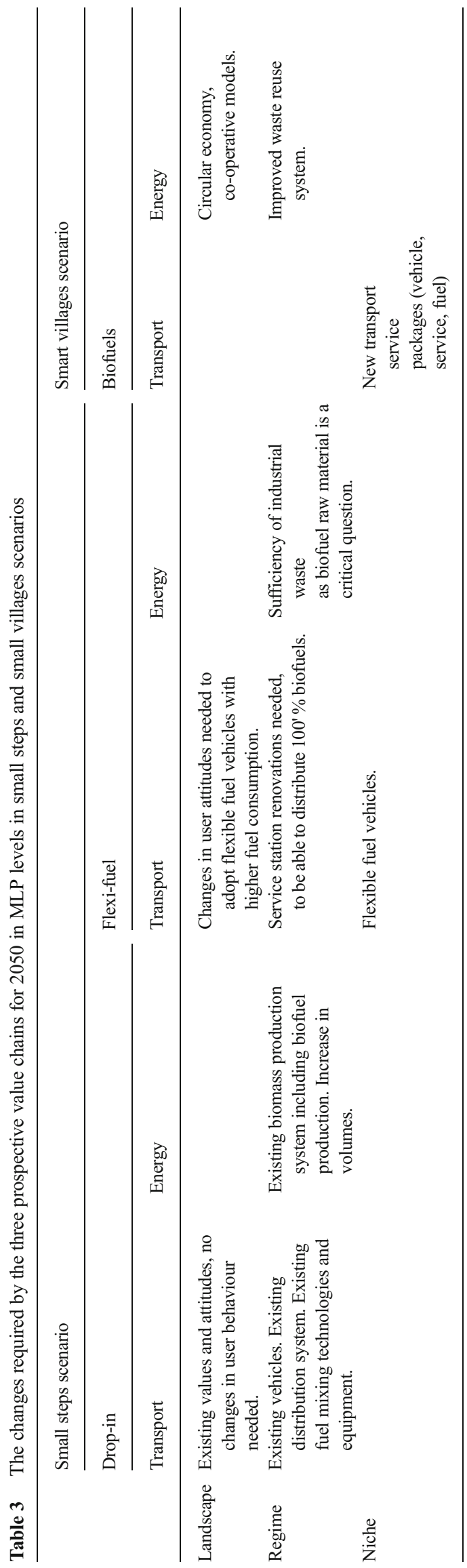




\section{Discussion and conclusions}

Our first research question focused on identifying the elements of participatory value network analysis towards a biofuel-based transport system. As an answer to the question, the paper presents a future-oriented approach with three steps: (1) building future contexts for the prospective value networks, (2) identification of value networks and network actors and (3) analysing the value networks and chains and finding the major elements needing change in the system.

The second research question sought the approach's benefits for various transport system actors to understand and advance changes required for such a transition. The approach provides both policy and business world actors a transition arena to discuss and build the future together through value network analysis, which concretises the actions required in the future. Consequently, the approach contributes to business renewal of companies and potential market creation of the public sector as well.

The third research question enquired about the benefits of the participatory analysis for public and private decision making. The approach and its results provide an important foresight element to decision making towards sustainable solutions. It integrates methods from various theoretical backgrounds and shows to policy-makers, on the one hand, the prerequisites of the change (scenarios of the future) and on the other, the possibilities of different actors to shape the transition towards the desired direction (value networks and chains).

The proposed participatory approach proved applicable in a practical situation and with a variety of stakeholders. Future research is, however, needed to clarify some methodological and practical questions. These relate to communication and visualisation of value network theory to the work shop participants in a clear and concise manner. Also the regulation-oriented approach in scenario building needs some adjustments and consideration of future markets and their prerequisites as equally important drivers for change.

Our approach demonstrated that in the future's renewable road transport system, transport and energy systems will need to be more integrated than today and that the potential for new business will lie in the intersections of the current transport and energy systems. The number of multi-actors having roles related both to transportation and energy production and delivery will increase. A biorefinery, producing energy, chemicals and fuels is an example of such a multi-actor.

The case exercise showed that the future path of the Finnish renewable transport system depends strongly on today's choices and decisions. For example, cars that are designed and produced today will still be in use in 2050. With regard to biofuel infrastructure and actors, in the Small Step scenario, very little changes are required from the present situation. In the Smart Villages scenario, instead, a circular economy based on local energy production from industrial by-products will require remarkable changes. Industrial by-products are not, at least in the light of the present knowledge, a sufficient source of raw material for biofuels. By-products are always bound to the main production line, and consequently, dependent on the demand of the main product. This indicates that biofuel value networks depend greatly on external influences, i.e., the scenario setting.

In conclusion, the participatory, prospective value network approach we propose widens the scope of system actors from linear value chain thinking to a transition-oriented network approach. It creates a transition arena in our case for biofuel stakeholders to create and share the same image of the future's transport system, based on renewable energy. It also helps them to find complementary measures to support the transition in markets, regulations, policies, values, resources, technologies and infrastructures. Identification of value networks and further value chains is important, since they concretise the actions and actors required for renewable biofuel production and use in the future. The approach allows direct knowledge diffusion to the decision makers, which makes it as a supportive element to strategic planning and decision making, for both public and private stakeholders.

In our view prospective value networks and chains describe the future business logics and their prerequisites and manifest therefore future regimes. Participatory, prospective value network analysis enables the recognition of possible future actors, actions and their combinations, which again form value creation possibilities. The prospective value network process also helps various system actors to consider landscape-level constraints, like changes in values and global trends, and also the needs which guide the society to change the existing regime, e.g., towards renewable energy use. Participatory value network analysis may be applied to various sectors of the society, not just to transport. It may act as a tool to increase the knowledge of different actors in making decisions towards low-carbon futures.

Acknowledgments The research work presented in this paper was carried out as a part of the TOP-NEST (Nordic Pathways for Sustainable Transport and Energy) research project, under Nordic Energy Research Sustainable Energy Systems 2050 research funding programme, which is gratefully acknowledged. The authors also wish to thank all TOP-NEST project WP4 researchers: Lars Coenen (Circle Lund), Lars J. Nilsson (Lund University), Alexandra Nikoleris (Lund University), Antje Klitkou (NIFU), Dorothy Sutherland (NIFU), Eric Iversen (NIFU), Simon Bolwig (DTU), Sara Ben Amer (DTU), Juhani Laurikko (VTT), Tiina Koljonen (VTT) and Annele Eerola (VTT) for their valuable contribution.

Open Access This article is distributed under the terms of the Creative Commons Attribution 4.0 International License (http:// creativecommons.org/licenses/by/4.0/), which permits unrestricted use, distribution, and reproduction in any medium, provided you give appropriate credit to the original author(s) and the source, provide a link to the Creative Commons license, and indicate if changes were made. 


\section{Appendix}

Table 4 'Drop-in' value chain 2050 in small steps scenario

\begin{tabular}{|c|c|c|c|}
\hline Actors & $\begin{array}{l}\text { Value generation } \\
\text { (What?) }\end{array}$ & $\begin{array}{l}\text { Prerequisites for value generation } \\
\text { (By what means?) }\end{array}$ & Supporting activities \\
\hline Consumer & Transport km & Existing vehicles & \\
\hline Vehicle manufacturer & Existing vehicles (diesel) & Existing vehicles & \\
\hline Distributor & Distribution & Mixing of fuel & Mixing of fuel commitment \\
\hline \multicolumn{4}{|l|}{ Tax model } \\
\hline Logistics & Existing & Existing & \\
\hline Biorefinery & Production & $\begin{array}{l}\text { Mixing of fuel commitment, } \\
\text { or other subsidy }\end{array}$ & $\begin{array}{l}\text { Potential BtL (Biomass to Liquid) process } \\
\text { investment subsidies and new investments }\end{array}$ \\
\hline \multicolumn{4}{|l|}{ R\&D subsidy } \\
\hline Logistics & Timber logistics & Existing & Infrastructure \\
\hline
\end{tabular}

Table 5 'FlexiFuel' value chain 2050 in small steps scenario

\begin{tabular}{|c|c|c|c|}
\hline Actors & $\begin{array}{l}\text { Value generation } \\
\text { (What?) }\end{array}$ & $\begin{array}{l}\text { Prerequisites for value generation } \\
\text { (By what means?) }\end{array}$ & Supporting activities \\
\hline Consumer & Transport km & $\begin{array}{l}\text { Suitable vehicles } \\
100 \% \text { ethanol cars consume more fuel than"fossil" } \\
\text { cars }(101 / 100 \mathrm{~km})\end{array}$ & Support: transport km cannot be too expensive \\
\hline Vehicle manufacturer & FFV-vehicles & Manufacturing FFV vehicles should be profitable & $\begin{array}{l}\text { EU subsidies needed (today car manufacturers do } \\
\text { not benefit from producing bioenergy vehicles) }\end{array}$ \\
\hline Distributor & Distribution & Service stations should have biofuel-suitable equipment & Service station renovations (100 \% biofuels) \\
\hline Logistics & Distribution & Own tanks for $100 \%$ biofuel & \\
\hline Industrial waste flows & $\begin{array}{l}\text { Waste refining } \\
\text { (biorefinery) }\end{array}$ & Industrial waste & $\begin{array}{l}\text { Neutral regulation (markets decide how "waste" is } \\
\text { utilised) }\end{array}$ \\
\hline Other industrial manufacturing & "Main product" & Enough production, volume & \\
\hline
\end{tabular}

Table 6 Biofuel value chain 2050 in Smart villages scenario

\begin{tabular}{|c|c|c|c|}
\hline Actors & $\begin{array}{l}\text { Value generation } \\
\text { (What?) }\end{array}$ & $\begin{array}{l}\text { Prerequisites for value generation } \\
\text { (By what means?) }\end{array}$ & Supporting activities \\
\hline $\begin{array}{l}\text { Food industry } \\
\text { - root debarking } \\
\text { - further processing }\end{array}$ & Waste $\rightarrow$ Raw material & Enough waste for raw material & \\
\hline $\begin{array}{l}\text { Agriculture } \\
\text { - field side streams } \\
\text { - livestock }\end{array}$ & Side streams $\rightarrow$ Raw material & Enough side streams for raw material & \\
\hline $\begin{array}{l}\text { Wood production } \\
\text { - forest industry companies } \\
\text { - private forest owners }\end{array}$ & Wood & Raw material availability (volume and quality) & \\
\hline $\begin{array}{l}\text { Technology providers } \\
\text { - raw material }\end{array}$ & Technology needed in the whole chain & Working markets for technology providers & $\mathrm{R} \& \mathrm{D}$, start-up assistance \\
\hline
\end{tabular}

- raw material

- processing 
Table 6 (continued)

\begin{tabular}{lll}
\hline Actors & $\begin{array}{l}\text { Value generation } \\
\text { (What?) }\end{array}$ & $\begin{array}{l}\text { Prerequisites for value generation } \\
\text { (By what means?) }\end{array}$ \\
\hline $\begin{array}{l}\text { - services } \\
\text { organising }\end{array}$ & Waste $\rightarrow$ Raw material & Supporting activities \\
$\begin{array}{l}\text { Trade } \\
\text { Transport company }\end{array}$ & Raw material collecting & Waw material \\
$\begin{array}{l}\text { Small refineries } \\
\text { Distribution company }\end{array}$ & Raw material processing & Suitable stock and enough raw material to transport \\
Consumers & Fuel to the vehicle & $\begin{array}{l}\text { Enough raw material and demand for the end product } \\
\text { Suitable stock and distribution logistics }\end{array}$ \\
Service providers & Total service (fuel as a part of total service) & Working service business \\
\end{tabular}

\section{References}

1. European Commission (2011) White paper, Roadmap to a single European transport area - towards a competitive and resource efficient transport system. COM, Brussels, 144 final, 28.3.2011

2. Geels FW (2004) From sectoral systems of innovation to sociotechnical systems: insights about dynamics and change from sociology and institutional theory. Res Policy 33(6-7):897-920

3. Geels FW (2005) Processes and patterns in transitions and system innovations: refining the co-evolutionary multi-level perspective. Technol Forecast Soc Chang 72(6):681-696

4. Geels FW, Schot J (2007) Typology of sociotechnical transition pathways. Res Policy 36(3):399-417

5. Gereffi G (1994) The organization of buyer-driven global commodity chains: how US retailers shape overseas production networks. In: Gereffi G, Korzeniewicz M (eds) Commodity chains and global capitalism. Greenwood Press, Westport

6. Kaplinsky R (2000) Spreading the gains from globalization: what can be learned from value chain analysis? IDS Working Paper 100. Brighton: IDS

7. Ponte S, Gibbon P (2005) Quality standards, conventions and the governance of global value chains. Econ Soc 34(1):1-31

8. Ponte S (2007) Governance in the value chain for South African Wine TRALAC working paper 9/2007. Trade Law Centre for Southern Africa, Stellenbosch

9. Riisgaard L (2009) Global value chains, labour organization and private social standards: lessons from east African cut flower industries. World Dev 37(2):326-340

10. Eerola A, Jörgensen B (2002) Technology foresight in the Nordic countries, A Report to the Nordic Industrial Fund, Oslo, Center for Innovation and Commercial Development, Risoe-R-1362(EN)

11. Martin BR (1995) Foresight in science and technology. Technology Analysis \& Strategic Management, Vol. 7, No. 2, 1995. Journals Oxford Ltd. pp. 139-168

12. Nonaka I (1994) A dynamic theory of organizational knowledge creation. Organ Sci 1(5):14-37

13. Leathard A, Leathard A (2003) Introduction. In: Interprofessional collaboration. From policy to practice in health and social care. Brunner \& Routledge, Hove

14. Glenn J (2003) Participatory methods. In: Futures Research Methodology-V2.0. The United Nations University, The Millennium Project

15. Geels FW, Kemp R (2007) Dynamics in socio-technical systems: typology of change processes and contrasting case studies. Technol Soc 29(4):441-455
16. Foxon TJ, Hammond GP, Pearson PJG (2010) Developing transition pathways for a low carbon electricity system in the UK. Technol Forecast Soc Chang 77(8):1203-1213

17. Geels FW (2012) A socio-technical analysis of low-carbon transitions: introducing the multi-level perspective into transport studies. J Transp Geogr 24(2012):471-482

18. Auvinen H, Tuominen A (2012) Safe and secure transport system 2100. Vision. VTT Technology 5 (2012)

19. van Bree B, Verbong GPJ, Kramer GJ (2010) A multi-level perspective on the introduction of hydrogen and battery-electric vehicles. Technol Forecast Soc Chang 77(2010):529-540

20. Tuominen A, Järvi T, Räsänen J, Sirkiä A, Himanen V (2007) Common preferences of different user segments as basis for intelligent transport system: case study - Finland. IET Intell Transp Syst 1(2):59-68

21. Richardson B (2005) Sustainable transport: analysis frameworks. J Transp Geogr 13(1):29-39

22. Steg L, Gifford R (2005) Sustainable transportation and quality of life. J Transp Geogr 13(1):59-69

23. Porter ME (1985) Competitive advantage, Ch. 1. The Free Press, New York, pp 11-15

24. Normann R, Ramirez R (1994) Designing interactive strategy: from the value chain to the value constellation. Wiley, Chichester

25. Peppard J, Rylander A (2006) From value chain to value network: insights for mobile operators. Eur Manag J 24(2-3):128-141

26. Allee V (2000) Reconfiguring the value network. J Bus Strateg 21(4):36-39

27. Valkokari K, Valjakka T, Kansola M (2011) Towards collaborative smart supply chains - capabilities for business development. Int $\mathbf{J}$ Enterp Netw Manag 4(4):380-399

28. Ahokangas P, Matinmikko M, Myllykoski J, Okkonen H (2012) Future scenarios, ecosystems and business models for cognitive radio systems. VTT Technology 55, VTT Helsinki, $54 \mathrm{p}$

29. UNIDO (2005) Unido technology foresight manual, Volume 1 organization and methods. United Nations Industrial Development Organization, Vienna, 246 p

30. Finnish Transport Safety Agency (2015) http://www.trafi.fi/ tietopalvelut/tilastot/tieliikenne. Accessed 13.2.2015

31. Huttunen MJ, Kuittinen V (2013) Suomen biokaasulaitosrekisteri n:o 16. University of Eastern Finland, Joensuu

32. Finnish Petroleum Federation (2015) http://www.oil.fi Accessed 13.2.2015

33. National Climate and Energy Strategy 2013. Ministry of employment and the economy. Finland 